\title{
FIELD TESTING OF THE SMBF FLUME
}

\author{
Costanza Di Stefano, Gian Vito Di Piazza, Vito Ferro
}

\section{Introduction}

Discharge measurements can be carried out by an indirect method employing a stage-discharge relationship and a measurement of the water level in a fixed section. This type of measurement is generally reliable when the morphologic evolution of the cross-section area is controlled and monitored. The water level measurement can be carried out by a water depth gauge, an ultrasonic probe, a searchlight cell, etc.

Venturi meters are often used in open channel flow $[1,2,3,8,14,15,16,17]$ and in the field condition to determine a downstream free (semi-modular) condition and negligible head losses due to their insertion in the measurement channel [9]. Venturi and Parshall flumes are widespread to measure open-channel discharge accurately for agricultural applications.

Venturi flumes consist of a local diminution of the channel width, achieved by locally thickening the channel side walls, in order to assure that the critical depth occurs in the narrow section for a free flow condition. The Venturi flume is generally inserted in a zero-slope channel since increasing of the channel slope requires a decresing of the contracted cross-section flume width in order to establish the critical depth. A small width of the narrow cross-section could induce sedimentation processes of solid particles transported by flow.

The Endress+Hauser commercialises, as an example, nine different models of the Venturi meter, whose plan configuration follows the shape of the streamlines and determines a gradual contraction from the inlet rectangular section, having a width $B$, to another still rectangular section, having a narrow width $B_{c}$.

Paper received 29.01.2007; accepted 25.06.2007

Dr. Costanza Di Stefano, Res., Ph.D., Dr. Carmelo Bruno Ph.D., Prof. Vito Ferro, Full Prof., Ph.D, 2007 - Karl Emil Hilgard Hydraulic Prize, Dipartimento di Ingegneria e Tecnologie Agro-Forestali, Università di Palermo, Viale delle Scienze, 90128 Palermo, Italy, vferro@unipa.it
Fig. 1 shows the model QV306 of the Endress+ Hauser Venturi meter installed at the outlet of SPA2 basin. For the nine models, characterized from different values of the length $L$ of the Venturi meter, of $B$ and $B_{c}$, a laboratory investigation for determining stage-discharge relationship was carried out. The manufacturing company supplies the values $(h, Q)$, where $h$ is the water depth measured in a section of the channel upstream of the Venturi meter and $Q$ is the discharge. The experimental runs were carried out for the free outflow condition, using an horizontal measurement flume and realizing, upstream of the Venturi meter, an inlet reach where the measurement of $h$ is carried out. The inlet reach had a length twice as greater as the Venturi meter length $L$.

According to Di Stefano and Ferro [10], the stagedischarge relationship of a generic Endress+Hauser Venturi meter, characterized by a narrow section of width $B_{c}(\mathrm{~m})$, can be expressed by the following equation:

$$
Q=1.8513 B_{c}^{0.9736} h^{1.5264}
$$

in which $Q=$ discharge measured in $\mathrm{m}^{3} \mathrm{~s}^{-1}$ and $h=$ water depth measured in $\mathrm{m}$. Reliability of a single stage-discharge relationship (eq.1) demonstrates that a condition of hydraulic similarity exists among the nine models commercialized by Endress+Hauser [10].

The Parshall flumes are not hydraulically similar [8] and therefore a single stage-discharge relationship cannot be established. The bottom configuration of the Parshall flume does not allow an easy installation into an existing channel and the downstream back slope bottom can induce sedimentation processes of the solid particles transported by flow. A correction of the measured discharge has to be introduced when the flume is subjected to lateral, longitudinal or combined lateral-longitudinal slope settlements [14].

Recently, a new device for measuring discharge in open channel flow was proposed by Samani and Magallanez [19] and was also tested for its insertion in a sloping channel by Baiamonte and Ferro [5].

The measurement principle of this flowmeter, which will be simply named SMBF, is based on estab- 


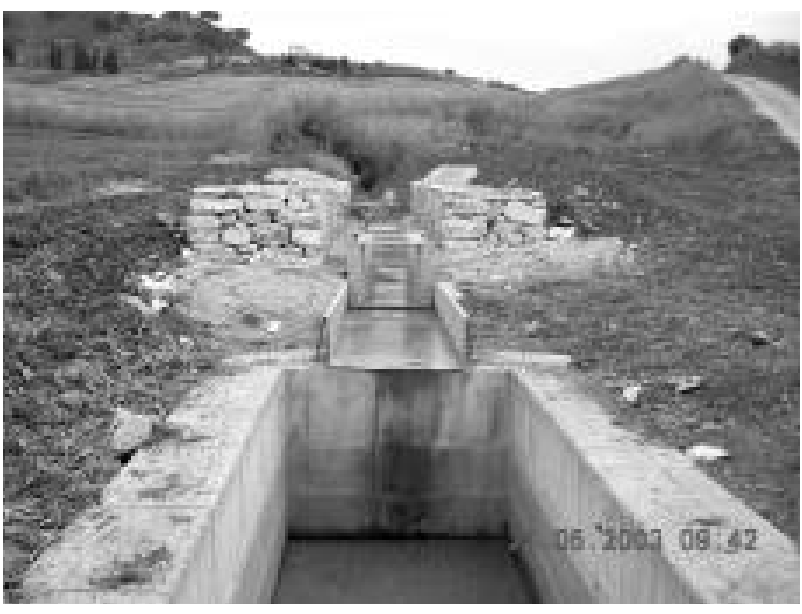

Fig. 1 - View of a Venturi channel commercialised by Endress+ Hauser installed at the outlet of SPA2 basin.

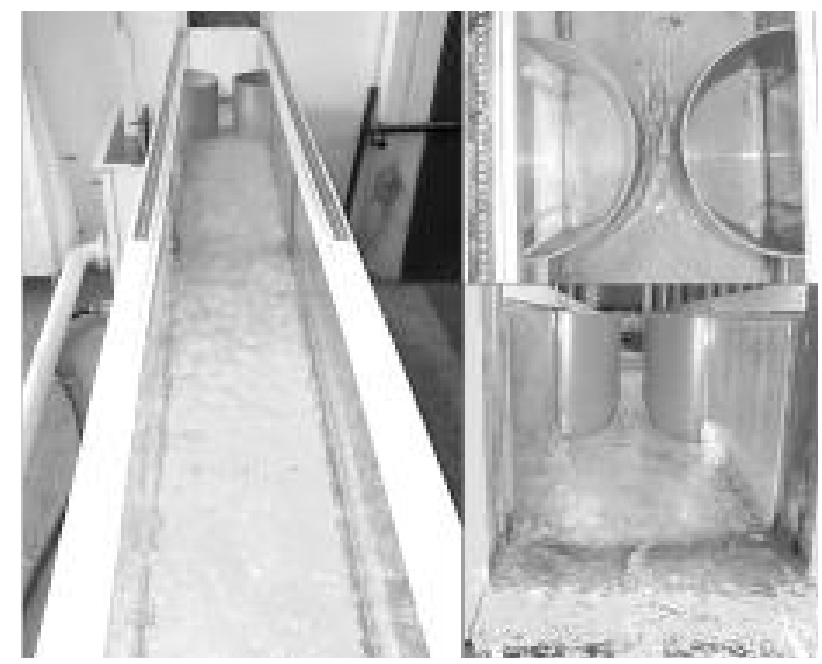

Fig. 2 - View of the laboratory flume and the SMBF flowmeter.

lishing a channel contraction $[16,18]$ using two semicylinders (Fig. 2) applied to the walls of a laboratory channel, having a zero slope. The width $B$ of the channel rectangular cross-section is narrowed to the throat width $B_{c}$. The diameter of the cylinders has been established for determining the chosen values of contraction ratio $r=B_{c} / B$.

At first in this paper, using both dimensional analysis and the theory of the incomplete self-similarity, the stage-discharge relationship of the SMBF flume is reviewed.

Then, the results of some experimental runs carried out using horizontal SMBF flumes characterized by different values of the contraction ratio (ranging from 0.17 to 0.81 ) are used for determining the two coefficients of the power stage-discharge equation.

Finally, the SMBF stage-discharge equation is tested using flow measurements carried out, in the period December 2004 - March 2006 at the outlet of the Sicilian experimental SPA1 and SPA2 basins.

The aim of the field testing is to verify the influence on the stage-discharge relationship of the adopt- ed flume field-size. The used SMBF flume has the same contraction ratio of the laboratory tested one even if the same $r$ value is obtained by a different semycilinder diameter. The field discharge measurement, independently carried out by a Venturi flume, will allow to control if SMBF flumes having the same contraction ratio are hydraulically similar.

\section{Stage-discharge relationship of SMBF flume}

The relationship between the upstream water depth, $h$, and discharge, $Q$, for an horizontal flume constructed by contracting the flow from a channel width $B$ to a throat width $B_{c}$ is described by the following functional relationship [13]:

$$
F\left(Q, h, B, B_{c}, g, \mu\right)=0
$$

in which $F=$ functional symbol and $\mu=$ water viscosity.

According to the $\Pi$ - Theorem of dimensional analysis [7], the same functional relationship can be expressed using only three dimensionless groups:

$$
F\left(\Pi_{1}, \Pi_{2}, \Pi_{3}\right)=0
$$

where $\Pi_{1}, \Pi_{2}$, and $\Pi_{3}=$ dimensionless groups whose expression has to be determined.

The $\Pi$ theorem allows the organization of experimental runs and the analysis of measurements by dimensionless groups [11].

Choosing $B_{c}, g$, and $\mu$ as dimensional independent variables (i.e., as measurements units of a particular reference system), Ferro [12] showed that $\Pi_{1}, \Pi_{2}$, and $\Pi_{3}$ groups have the following expressions:

$$
\Pi_{1}=\frac{Q}{g^{1 / 2} B_{c}^{5 / 2}}=\left(\frac{K_{c}}{B_{c}}\right)^{3 / 2}
$$

where $K_{c}$ is the critical depth in the narrow section having a width $B_{c}$,

$$
\begin{aligned}
& \Pi_{2}=\frac{h}{B_{c}} \\
& \Pi_{3}=\frac{B}{B_{c}}
\end{aligned}
$$

Substituting Eqs. (4), (5), and (6) into Eq. (3) we obtain:

$$
F\left(\frac{K_{c}}{B_{c}}, \frac{h}{B_{c}}, \frac{1}{r}\right)=0
$$

Eq.(7) demonstrates that all SMBF flumes having the same contraction ratio are hydraulically similar.

Therefore, for given contraction ratio $r$ the stagedischarge relationship of the SMBF flume is expressed by the following functional relationship:

$$
\frac{K_{c}}{B_{c}}=\phi\left(\frac{h}{B_{c}}\right)
$$

According to incomplete self-similarity hypothesis 
$[6,7]$, Baiamonte and Ferro [5] showed that Eq. (8) is expressed by the following relationship:

$$
\frac{K_{i}}{B_{c}}=a\left(\frac{h}{B_{c}}\right)^{\prime \prime}
$$

in which $a$ and $n=$ numerical constants to be experimentally determined.

For determining $a$ and $n$ values the experimental runs carried out by Baiamonte and Ferro [4] in an horizontal flume located at the laboratory of Dipartimento di Ingegneria e Tecnologie Agro-Forestali of the University of Palermo were used.

The flowmeter investigated by Baiamonte and Ferro [4] was formed by creating a contraction of the flume cross section and was constructed by inserting two semi-cylinders in polyvinyl chloride (PVC) (Fig. 2).

Decreasing values of the contraction ratio $r=B_{c} / B$ were achieved by increasing the diameter of the installed semi-cylinders (Tab. 1).

Water depth $h$ was measured by a water depth gauge located, upstream of the flowmeter, at a distance equal to $B$ from the axis of the narrow section. The values of the diameter $\phi_{L}$ of the semi-cylinders, of the width of the narrow section $B_{c}$ and of the contraction ratio $r$ are listed in Tab. 1 .

For each value of the contraction ratio $r(0.17 \leq r \leq$ $0.81)$, Tab. 1 also lists the number $N$ of runs carried out and the values of $a$ and $n$ coefficients estimated by fitting eq. (9) to the experimental pairs $\left(h / B_{c}, K_{c} / B_{c}\right)$. Fig. 3 shows the comparison between all measured $K / B_{c}$ values and the ones $K_{c} * / B_{c} *$ calculated using eq.(9) with $a$ and $n$ values listed in Tab. 1. For an hor-

\begin{tabular}{|c|c|c|c|c|c|}
\hline$\phi_{\mathrm{L}}(\mathrm{cm})$ & $\mathrm{B}_{\mathrm{c}}(\mathrm{cm})$ & $\mathrm{r}$ & $\mathrm{N}$ & $\mathrm{a}$ & $\mathrm{n}$ \\
\hline 25.0 & 5.10 & 0.17 & 14 & 0.731 & 1.154 \\
\hline 22.5 & 7.70 & 0.26 & 12 & 0.721 & 1.087 \\
\hline 20.0 & 10.0 & 0.33 & 13 & 0.721 & 1.115 \\
\hline 14.0 & 14.5 & 0.48 & 17 & 0.703 & 1.066 \\
\hline 12.5 & 17.9 & 0.60 & 13 & 0.774 & 1.100 \\
\hline 6.30 & 24.2 & 0.81 & 14 & 0.880 & 1.118 \\
\hline
\end{tabular}

TABLE 1 - Values of the semycilinders diameter $\phi_{\mathrm{L}}$, narrow width section $\mathrm{B}_{\mathrm{c}}$, contraction ratio $\mathrm{r}$, a and $\mathrm{n}$ coefficients of eq. (9).

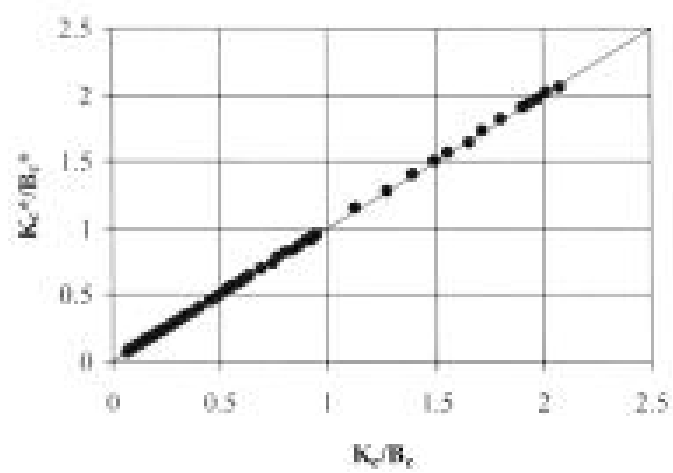

Fig. 3 - Comparison between the measured $\mathrm{K}_{\mathrm{c}} / \mathrm{B}_{\mathrm{c}}$ values and the ones $\mathrm{K}_{\mathrm{c}} * / \mathrm{B}_{\mathrm{c}} *$ calculated using $\mathrm{n}$ and a values listed in Table 1.

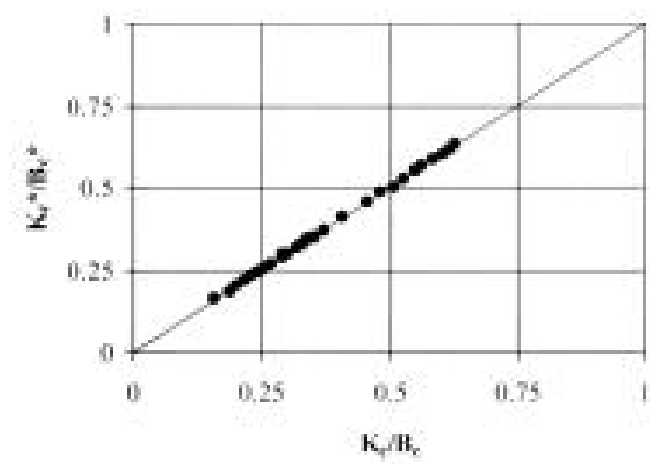

Fig. 4 - Comparison, for an horizontal flume with $r=0.48$ and $r=$ 0.33 , between the measured $\mathrm{K}_{\mathrm{c}} / \mathrm{B}_{\mathrm{c}}$ values and the ones $\mathrm{K}_{\mathrm{c}}{ }^{*} / \mathrm{B}_{\mathrm{c}}{ }^{*}$ calculated using eq.(9).

izontal SMBF flume having a contraction ratio $r$ equal to 0.48 (near to the contraction ratio $(r=0.5)$ of the flume installed at SPA1 basin) and 0.33 (as the flume installed at SPA2 basin), Fig.4 shows the comparison between measured $K / B_{c}$ values and the ones $K_{c} * / B_{c} *$ calculated using eq.(9) in which $a=0.703$ and $n=$ 1.066 for $r=0.48$ and $a=0.721$ and $n=1.115$ for $r=$ 0.33 .

\section{Field testing of SMBF flume}

The SMBF flume was installed at the outlet of two Sicilian experimental basins, named SPA1 and SPA2, located at the experimental station for soil erosion measurement "Sparacia" of the Agricultural Faculty of the Palermo University.

The experimental station is located in western Sicily, Italy, approximately $100 \mathrm{~km}$ south of Palermo.

The experimental SPA1 basin, having an area of 3.67 ha, is equipped by a measurement channel (Fig. 5) into which a Khafagi-Venturi (KV) meter and a SMBF flowmeter are installed.

The Venturi meter installed at the outlet of SPA1 basin is a model commercialized by Endress+Hauser for which the stage-discharge relationship (1) was de-

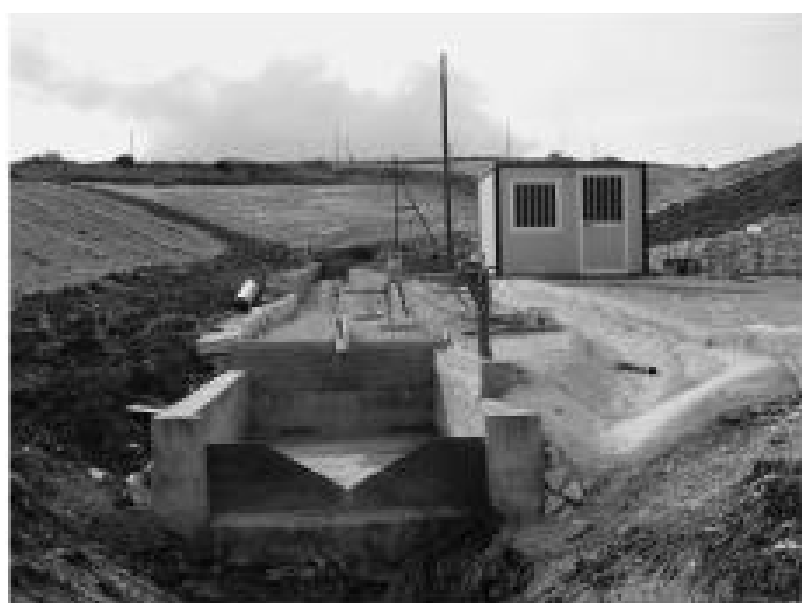

Fig. 5 - View of SPA1 measurement channel. 
terminated by a theoretical analysis and calibrated by accurate experimental laboratory runs [10], i.e. the field installed $\mathrm{KV}$ flume is geometrically equal to the one laboratory tested [10] for obtaining the stage-discharge relationship (1).

In other words, the field discharge measurement was carried out at the outlet of SPA1 basin using the same KV flume tested by a laboratory investigation [10] and for this reason the $\mathrm{KV}$ measurement is assumed as reference discharge for calibrating the SMBF flume.

The channel is $16 \mathrm{~m}$ long, with a rectangular crosssection (width of $0.12 \mathrm{~m}$ and height of $0.3 \mathrm{~m}$ ) and an horizontal bottom. The Khafagi-Venturi meter is characterized by a contracted cross-section width equal to $0.048 \mathrm{~m}$

The SMBF flowmeter (Fig. 6) was constructed narrowing the cross-section width $(B=0.12 \mathrm{~m})$ by two semi-cylinders having a radius equal to $0.03 \mathrm{~m}$ (contraction ratio $r$ equal to 0.5 ).

For the field installed SMBF flume a $a$ value equal to 0.703 and $n=1.066$ were assumed, even if the same contraction ratio $(r=0.48)$ was obtained in field using two semi-cylinders having a diameter $\phi_{\mathrm{F}}(6 \mathrm{~cm})$ less than the one $\phi_{\mathrm{L}}(14 \mathrm{~cm})$ used in the laboratory

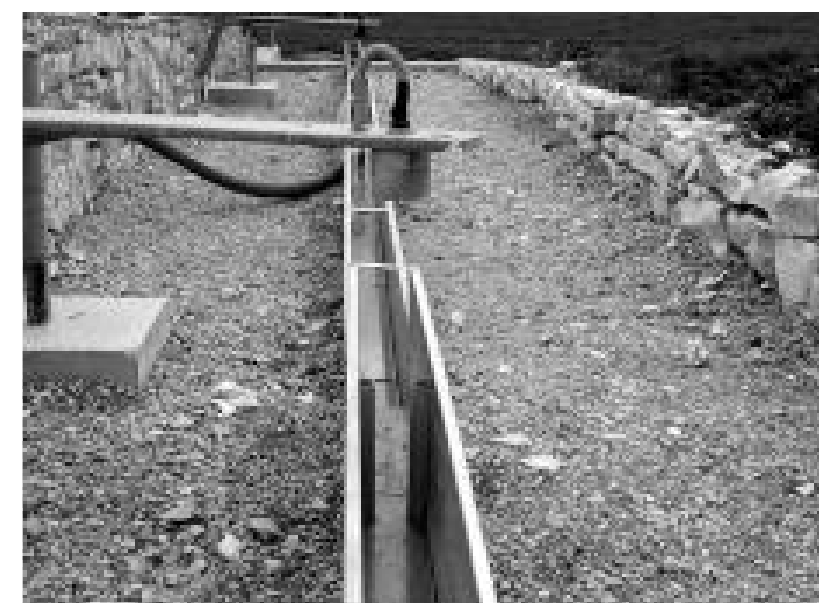

Fig. 6 - View of the SMBF flowmeter installed in SPA1 measurement channel.

tests. In other words, according to eq. (7), the field and laboratory SMBF flumes having the same contraction ratio were considered hydraulically similar.

The KV meter is installed in the cross-section having a distance of $4 \mathrm{~m}$ from the end of the measurement channel while the SMBF flowmeter is located

\begin{tabular}{|c|c|c|c|c|c|c|}
\hline $\begin{array}{l}\text { Event } \\
\text { (month/day/year) }\end{array}$ & $\begin{array}{c}P \\
{[\mathrm{~mm}]}\end{array}$ & $\begin{array}{c}Q_{p} \\
{\left[\mathrm{dm}^{3} / \mathrm{s}\right]}\end{array}$ & $\begin{array}{c}V \\
{\left[\mathrm{~m}^{3}\right]}\end{array}$ & $\begin{array}{c}Y \\
{[\mathrm{~kg}]}\end{array}$ & $\begin{array}{c}c \\
{\left[\mathrm{~g} \mathrm{dm}^{-3}\right]} \\
\end{array}$ & $a$ \\
\hline $12 / 09 / 2004$ & 29.4 & 1.45 & 5.85 & \multirow[b]{2}{*}{4.33} & \multirow[b]{2}{*}{0.51} & 0.642 \\
\hline $12 / 11-12 / 2004$ & 6.4 & 1.06 & 2.65 & & & 0.541 \\
\hline $12 / 16-17 / 2004$ & 57.2 & 14.98 & 324.83 & \multirow[b]{6}{*}{15.18} & \multirow[b]{6}{*}{0.04} & 0.727 \\
\hline $12 / 18-19 / 2004$ & 9.8 & 7.33 & 39.32 & & & 0.708 \\
\hline 12/20/2004(3:40 a.m.-6:00 a.m.) & 2.4 & 1.03 & 3.05 & & & 0.553 \\
\hline 12/20/2004(11:30 a.m.-15:50 p.m.) & 3.2 & 3.88 & 15.93 & & & 0.683 \\
\hline 12/20/2004(16:40 p.m.-23:59 p.m.) & 2.8 & 4.18 & 26.12 & & & 0.696 \\
\hline $12 / 21 / 2004$ & 1.8 & 0.93 & 5.12 & & & 0.554 \\
\hline $12 / 26 / 2004$ & 20.0 & 13.47 & 176.18 & & & 0.717 \\
\hline $12 / 26-27 / 2004$ & 11.4 & 16.37 & 138.62 & & & 0.695 \\
\hline $12 / 27-28 / 2004$ & 8.0 & 5.27 & 139.16 & & & 0.700 \\
\hline $02 / 19-21 / 2005$ & 13.2 & 8.57 & 170.87 & 3.68 & 0.02 & 0.592 \\
\hline $02 / 28-03 / 01 / 05$ & 14.0 & 3.00 & 75.69 & \multirow[b]{2}{*}{7.63} & \multirow[b]{2}{*}{0.01} & 0.693 \\
\hline 03/01-02/2005 & 23.0 & 16.98 & 503.84 & & & 0.712 \\
\hline 04/04-05/2005 & 22.0 & 0.35 & 9.37 & & & 0.417 \\
\hline $04 / 05-06 / 2005$ & 9.8 & 0.88 & 20.30 & & & 0.528 \\
\hline $04 / 11-13 / 05$ & 59.0 & 16.62 & 940.26 & 10.60 & 0.01 & 0.702 \\
\hline $12 / 11 / 2005$ & 17.2 & 2.44 & 5.16 & \multirow[b]{2}{*}{40.73} & \multirow[b]{2}{*}{0.08} & 0.376 \\
\hline $12 / 13-15 / 2005$ & 80.6 & 15.02 & 533.42 & & & 0.656 \\
\hline $12 / 27-28 / 2005$ & 15.4 & 3.50 & 27.39 & & & 0.618 \\
\hline $01 / 01-04 / 2006$ & 12.8 & 2.44 & 77.48 & & & 0.529 \\
\hline $01 / 31-02 / 01 / 06$ & 16.0 & 16.57 & 414.15 & & & 0.700 \\
\hline $02 / 23 / 2006$ & 8.8 & 1.31 & 10.73 & & & 0.545 \\
\hline $02 / 25-26 / 2006$ & 9.4 & 3.78 & \begin{tabular}{|l}
84.81 \\
\end{tabular} & \multirow[b]{2}{*}{28.95} & \multirow[b]{2}{*}{0.06} & 0.661 \\
\hline $02 / 27-28 / 2006$ & 14.8 & 16.36 & 408.57 & & & 0.694 \\
\hline $03 / 11-14 / 2006$ & 28.4 & 6.67 & 165.85 & & & 0.658 \\
\hline
\end{tabular}

TABLE 2 - Main data of the available runoff events (SPA1 basin). 
$0301-022005$

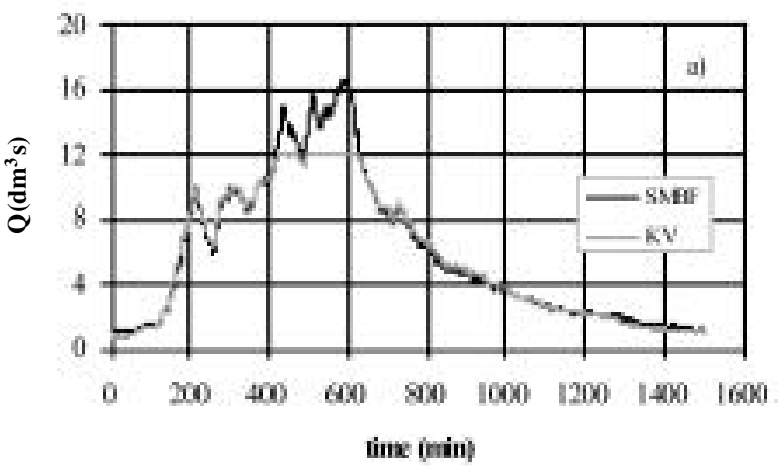

$02 / 23 / 2006$

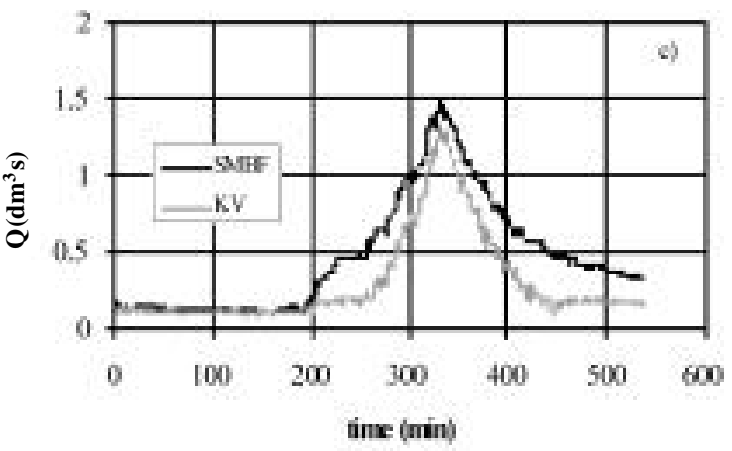

$01 / 31-0201 / 2006$

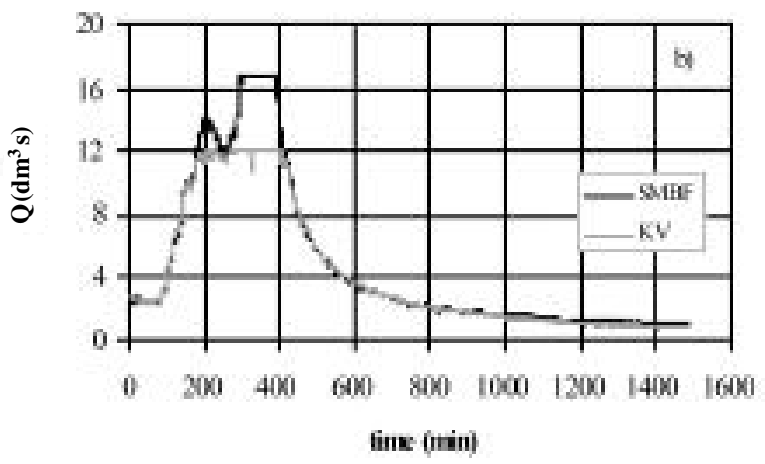

$0311-142006$

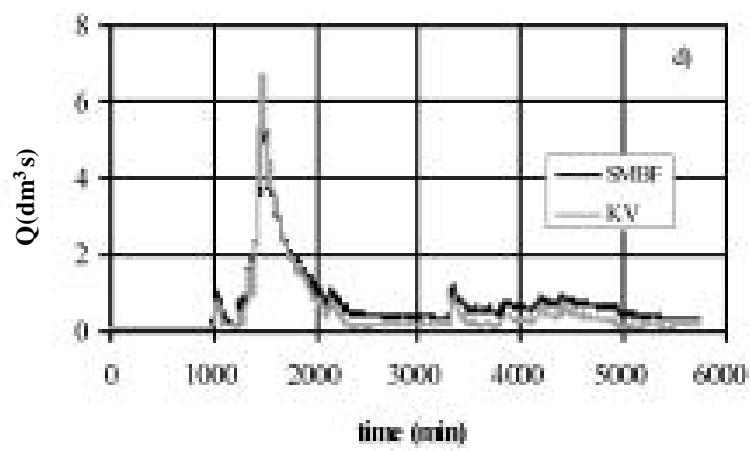

Fig. 7 - Examples of hydrographs monitored at SPA1 experimental basin using the KV and SMBF flumes

$7.5 \mathrm{~m}$ upstream the Khafagi-Venturi flume. Upstream of each flume an ultrasonic probe allows a time-continuous monitoring of the water depth. The measurement channel ends into a concrete sedimentation tank.

In the period December 2004 - March 2006, twenty-six hydrographs were monitored and are available for field testing of the stage-discharge relationship of SMBF flowmeter.

For some high rainfall events a measurement limit of the Khafagi-Venturi meter was identified. The installed KV flume was able to measure discharge less than or equal to $12 \mathrm{dm}^{3} \mathrm{~s}^{-1}$. The discharge of $12 \mathrm{dm}^{3}$ $\mathrm{s}^{-1}$ corresponds to the maximum upstream water depth, quasi equal to $25 \mathrm{~cm}$, permitting the openchannel flow working of the flume.

For each monitored event, Tab. 2 lists the date (month/day/year) of the rainfall-runoff event, the event rainfall depth $P(\mathrm{~mm})$, the peak discharge $Q_{p}$ $\left(\mathrm{dm}^{3} \mathrm{~s}^{-1}\right)$, the hydrograph volume $V\left(\mathrm{~m}^{3}\right)$, the sediment yield $Y(\mathrm{~kg})$ and the mean sediment concentration $c\left(\mathrm{~g} \mathrm{dm}^{-3}\right)$.

For each rainfall-runoff event, the availability of two independent discharge measurements (KV flume and SMBF flume) allowed to obtain the corresponding hydrographs (Fig. 7).

The comparison between the two hydrographs measured by the KV and the SMBF flume showed some cases of overlaying between the hydrographs (Fig. 7a) and some cases (Fig. 7c) in which appreciable differences into the discharge values occur.
Using each monitored hydrograph by the $\mathrm{KV}$ flume (reference flume) a field calibration of the SMBF flume was carried out. In other words, using the discharge values measured by the KV flume, the corresponding water depth measured upstream the SMBF flume and eq.(9) with $n=1.066$, the value of the scale coefficient $a$ of the stage-discharge relationship was calibrated. For each rainfall-runoff event Tab. 2 also lists the $a$ values estimated by field measurements.

For each investigated event, Fig. 8 shows the $a$ values (Tab. 2) plotted versus the peak discharge $Q_{p}$. For $Q_{p}$ values greater than $3 \mathrm{dm}^{3} \mathrm{~s}^{-1}$ a constant value of the scale coefficient $a$, equal to 0.683 , can be assumed. The field value of the scale coefficient $a$ $(0.683)$ is very near to the value $(0.703)$ estimated by laboratory measurements. Field using of the laboratory value of the scale coefficient will produce a negligible discharge overestimation equal to $4.4 \%$. This result confirms that for $r=0.5$ the SMBF field flume is hydraulically similar to the laboratory tested one even if the diameter $\phi_{\mathrm{L}}$ of the semi-cylinders installed for laboratory runs $(14 \mathrm{~cm})$ is 2.3 times the radius $\phi_{\mathrm{F}}(6$ $\mathrm{cm})$ used in field installation $\left(\phi_{\mathrm{L}} / \phi_{\mathrm{F}}=2.3\right)$.

For monitoring erosion processes in the experimental SPA2 basin, having an area of 30 ha, a measurement channel and a sedimentation tank were built in a straight stream reach just upstream of the basin outlet. The channel is $12.6 \mathrm{~m}$ long, with a rectangular cross-section and an horizontal bottom. To ensure an 


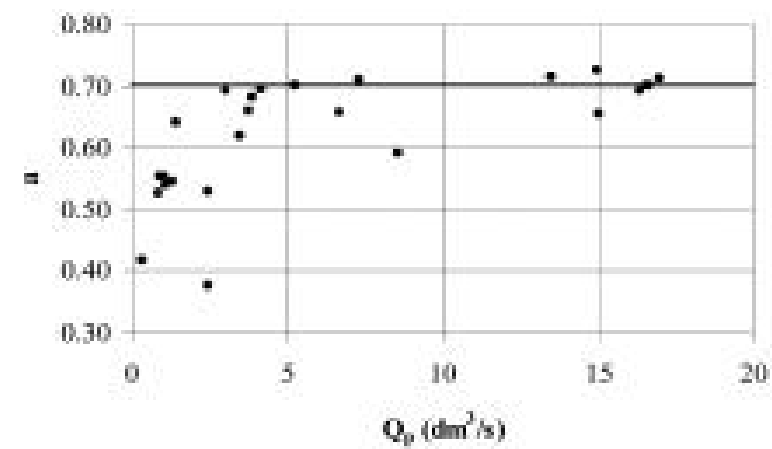

Fig. 8 - Values of a coefficient listed in Table 2 plotted versus the corresponding peak discharge.

undisturbed flow inlet in the measurement channel, the channel has a converging transition reach.

The measurement channel is equipped by both a $\mathrm{KV}$ meter and the SMBF flowmeter. Upstream each flume an ultrasonic probe is installed for a time-continuous monitoring the water depth. The Venturi meter is the type QV 306 commercialized by Endress+ Hauser. The SMBF flowmeter installed in SPA2 basin (Fig. 9) was constructed narrowing the cross-section width $(B=0.60 \mathrm{~m})$ by two semi-cylinders having a radius equal to $0.20 \mathrm{~m}$ (contraction ratio $r$ equal to 0.33 ). For the field installed SMBF flume $a=0.721$ and $n$ value equal to 1.115 obtained by laboratory runs (Tab. 1) were assumed. In other words, the field installed SMBF flume was assumed hydraulically similar to the one tested by laboratory runs, even if the same contraction ratio $(r=0.33)$ was obtained in field using two semi-cylinders having a diameter $\left(\phi_{\mathrm{F}}\right.$ $=40 \mathrm{~cm})$ equal twice the one $\left(\phi_{\mathrm{L}}=20 \mathrm{~cm}\right)$ used in the laboratory tests $\left(\phi_{\mathrm{L}} / \phi_{\mathrm{F}}=0.5\right)$.

The KV meter is installed near the end of the measurement channel while the SMBF flowmeter is located $6.40 \mathrm{~m}$ upstream the Khafagi-Venturi flume.

In the period December 2005 - March 2006, five rainfall events able to produce runoff occurred. Five hydrographs were monitored and used for field testing of the stage-discharge relationship of SMBF flowmeter.

For each monitored event, Tab. 3 lists the date of the rainfall-runoff event, the event rainfall depth $P$ (mm), the peak discharge $Q_{p}\left(\mathrm{dm}^{3} \mathrm{~s}^{-1}\right)$, the hydrograph volume $V\left(\mathrm{~m}^{3}\right)$, the sediment yield $Y(\mathrm{~kg})$ and

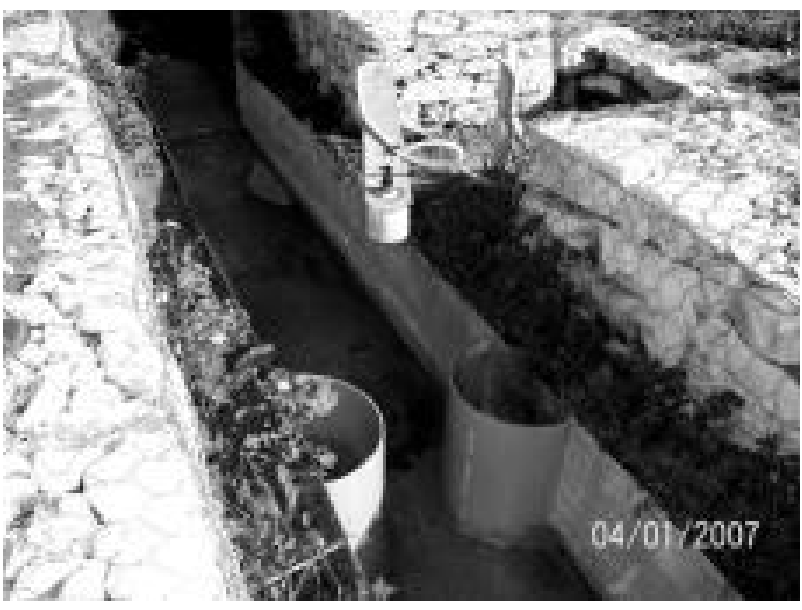

Fig. 9 - View of the SMBF flowmeter installed in SPA2 measurement channel.

the mean sediment concentration $c\left(\mathrm{~g} \mathrm{dm}^{-3}\right)$.

For each rainfall-runoff event, the availability of two independent discharge measurements (KV flume and SMBF flume) allowed to obtain the corresponding hydrographs (Fig. 10).

For the SPA2 basin, the comparison between the two hydrographs measured by the KV and the SMBF flume showed some cases of overlaying between the hydrographs (Fig. 10a) and some cases (Fig. 10c) in which appreciable differences into the discharge values occur.

Using the discharge values measured by the $\mathrm{KV}$ flume, the corresponding water depth measured upstream the SMBF flume and eq.(9) with $n=1.115$, the value of the scale coefficient $a$ of the stage-discharge relationship was calibrated. For each rainfall-runoff event Tab. 3 also lists the $a$ values estimated by field measurements.

For each investigated event, Fig. 11 shows the $a$ values (Tab. 3) plotted versus the peak discharge $Q_{p}$. For $Q_{p}$ values greater than $30 \mathrm{dm}^{3} \mathrm{~s}^{-1}$ a constant value of the scale coefficient $a$, equal to 0.620 , can be assumed. The field value of the scale coefficient $a$ $(0.620)$ is not coincident with the value $(0.721)$ estimated by laboratory measurements. Field using of the laboratory value of the scale coefficient will produce a discharge overestimation equal to $25.5 \%$.

\begin{tabular}{|c|c|c|c|c|c|c|}
\hline $\begin{array}{l}\text { Event } \\
\text { (month/day/year) }\end{array}$ & $\begin{array}{c}P \\
{[\mathrm{~mm}]}\end{array}$ & $\begin{array}{c}Q_{p} \\
{\left[\mathrm{dm}^{3} / \mathrm{s}\right]}\end{array}$ & $\begin{array}{c}V \\
{\left[\mathrm{~m}^{3}\right]}\end{array}$ & $a$ & $\begin{array}{c}Y \\
{[\mathrm{~kg}]} \\
\end{array}$ & $\begin{array}{c}c \\
{\left[\mathrm{~g} \mathrm{dm}^{-3}\right]}\end{array}$ \\
\hline $12 / 11 / 2005$ & 17.2 & 29.76 & 67.84 & 0.583 & \multirow[b]{2}{*}{1694} & \multirow[b]{2}{*}{0.34} \\
\hline $12 / 13-15 / 2005$ & 80.6 & 115.67 & 4945.18 & & & \\
\hline $12 / 27-28 / 2005$ & 13.8 & 30.86 & 213.31 & 0.652 & & \\
\hline $02 / 23 / 2006$ & 8.8 & 13.94 & 73.71 & 0.512 & & \\
\hline $02 / 25-26 / 2006$ & 9.4 & 35.4 & 230.77 & 0.594 & \multirow[b]{2}{*}{1864} & \multirow[b]{2}{*}{0.66} \\
\hline $02 / 27-28 / 2006$ & 14.8 & 115.24 & 2471.86 & & & \\
\hline $03 / 11-12 / 2006$ & 22.0 & 52.91 & 825.10 & 0.650 & & \\
\hline
\end{tabular}

TABLE 3 - Main data of the available runoff events (SPA2 basin). 


\section{$12 / 11 / 2005$}

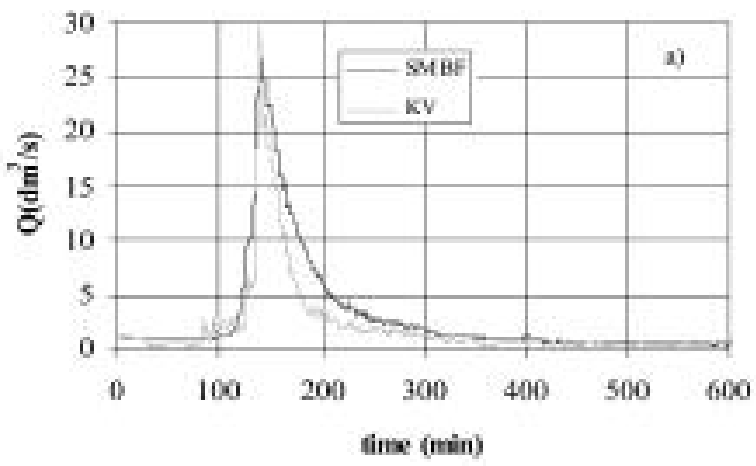

$02 / 23 / 2006$

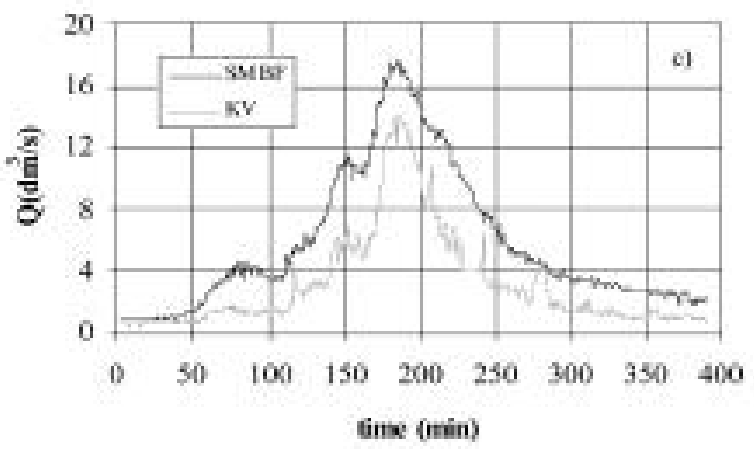

$12 / 27-28 / 2005$

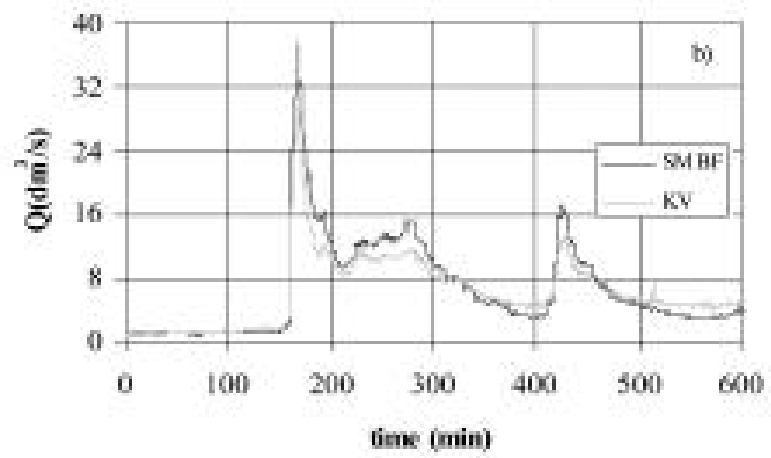

$02 / 25-26 / 2006$

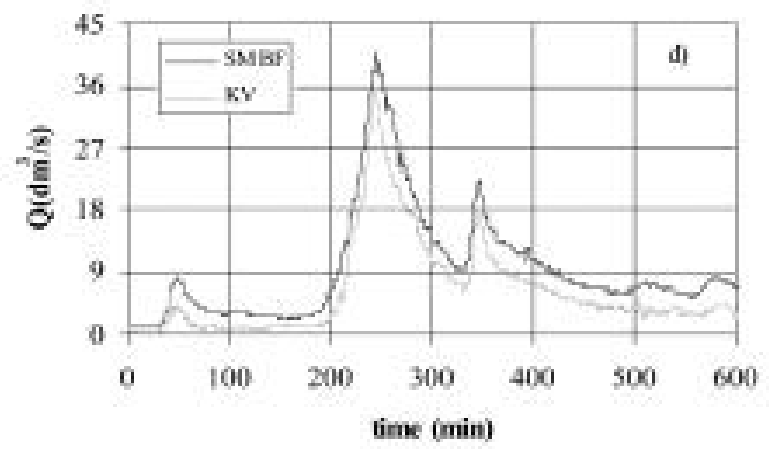

Fig. 10- Examples of hydrographs monitored at SPA2 experimental basin using the KV and SMBF flumes.

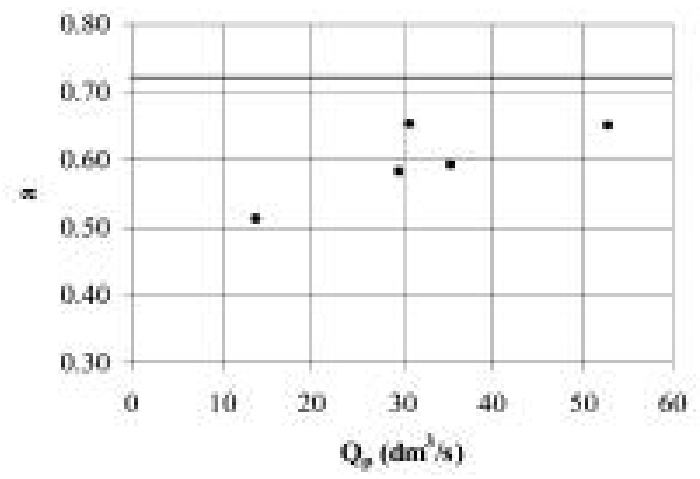

Fig. 11 - Values of a coefficient listed in Table 3 plotted versus the corresponding peak discharge.

This result underlines that for the SMBF flume installed at the outlet of SPA2 basin some scale effects could be detected. Taking into account that for $r=$ 0.33 different values of the scale coefficient $a$ of the stage-discharge relationship were obtained for field ( $a$ $=0.620)$ and laboratory $(a=0.721)$ conditions, this result could be dependent of the ratio $\phi_{\mathrm{L}} / \phi_{\mathrm{F}}=0.5$.

Field using of the SMBF flume for the SPA2 basin needs to be tested using other rainfall-runoff events. Other field measurements of the pairs depth-discharge needs in order to test if the scale coefficient can be assumed constant for discharge values greater than $30 \mathrm{dm}^{3}$ $\mathrm{s}^{-1}$ and if the discrepancies between the laboratory and the field value of the scale coefficient can be explained by other effects (sediment transport, scale effects).
If the results obtained for SPA2 basin will be confirmed by other field measurements, this investigation will prove that, for a given contraction ratio, a field SMBF flume is not hydraulically similar to the laboratory tested one (i.e. the flumes are not characterized by the same $a$ coefficient of the stage-discharge relationship) if the ratio $\phi_{\mathrm{L}} / \phi_{\mathrm{F}}$ is greater than 1 .

\section{Conclusions}

The experimental installations for measuring sediment yield of a small river basin must be equipped with discharge flowmeters. The flumes must be semimodular, should able to induce small head losses due to their insertion in the measurement channel and their geometry should not promote sedimentation processes at the measuring section. Small Venturi flumes with flat bottom and Parshall flumes are diffusely employed and inserted in horizontal bottom channels.

Recently Samani and Magallanez proposed a new flume (SMBF flume) realized by introducing in the measuring rectangular channel two semis-cylinders establishing a contraction of the rectangular cross-section. The SMBF flume is characterized by a power stage-discharge relationship whose coefficients were determined using the results of a wide experimental investigation carried out in a laboratory physical model.

This investigation verified the applicability of the theoretical stage-discharge relationship, calibrated by 
laboratory measurements, using twenty-six hydrographs monitored at SPA1 experimental basin by a SMBF flowmeter having a contraction ratio equal to 0.5 and five hydrographs monitored at SPA2 experimental basin by a SMBF flowmeter having a contraction ratio equal to 0.33 .

The analysis showed that for each SMBF flume the field value of the scale coefficient ( 0.683 for SPA1 and 0.620 for SPA2) is near to the value $(0.703$ for SPA1 e 0.721 for SPA2) estimated by laboratory measurements. Using of the laboratory value of the scale coefficient for field application produced a negligible discharge overestimation equal to $4.4 \%$ for SPA1 basin, while an appreciable overestimation equal to $25.5 \%$ occurred for SPA2 basin.

For SPA2 basin other field measurements of the pairs depth-discharge are required to test both if the scale coefficient can be assumed constant for discharge values greater than $30 \mathrm{dm}^{3} \mathrm{~s}^{-1}$ and if the discrepancies between the laboratory and the field value of the scale coefficient can be explained by other effects.

Further field investigations carried out by the SMBF flume could prove that no scale effects between laboratory and field flume occur if the ratio between the diameter of the semi-cylinders used in laboratory and the one used in field is greater than one.

\section{Acknowledgements}

This research is supported by a grant from DESERTNET2 Project.

Prof. Ferro set up the research. All Authors analysed the results and participated in writing the paper.

\section{References}

[1] Aвt S.R., Thompson K., STAKer K., Discharge correction for longitudinal settlement of Parshall flumes, Transactions of the ASAE (1989) 35 (2), 1541-1544.

[2] Aвt S.R., COоK C., Staker K.J., Johns D.D., Small Parshall flume rating correction, J. Hydr. Engrg., ASCE (1992) 118 (5), 798-803.

[3] Abt S.R., Florentin C.B., Genovez A., Ruth B.C., Settlement and submergence adjustments for Parshall flume, J. Irr. and Drain. Engrg., ASCE (1995) 121 (5), 317-321.

[4] Baiamonte G., Ferro V., Indagine sperimentale su un semplice misuratore di portata per correnti a pelo libero su fondo inclinato, Quaderni di Idronomia Montana (2005) 24, 73-92 (in Italian).

[5] Baiamonte G., Ferro V., Simple flume for flow measurement in sloping open channel, J. Irr. and Drain. Engrg., ASCE (2007) 133 (1), 71-78.

[6] BarenblatT G.I., Similarity, self-similarity and intermediate asymptotics, (1979), Consultans Bureau, New York.

[7] Barenblatt G.I., Dimensional Analysis, (1987), Gordon and Breach Science, Amsterdam, The Netherlands.
[8] BlaisDell F.W., Results of Parshall flume tests, J. Irr. and Drain. Engrg., ASCE (1994) 120 (2), 278-291.

[9] De Marchi G., Citrini D., Noseda G., Nozioni di Idraulica con particolare riguardo ai problemi delle bonifiche e delle irrigazioni, (1977), Edagricole, Bologna (in Italian).

[10] Di Stefano C., Ferro V., Monitoraggio dei processi erosivi e calibrazione di un modello distribuito in un piccolo bacino siciliano, Rivista di Ingegneria Agraria (2002) 2, 47-58 (in Italian).

[11] FERRO V., Applying the hypothesis of self-similarity for flow resistance law of small-diameter plastic pipes, $\mathrm{J}$. Hydr. Engrg., ASCE (1997) 123 (3), 175-179.

[12] FERro V., Discussion of "Simple flume for flow measurement in Open Channel" by Zohrab Samani and Henry Magallanez, J. Irr. and Drain. Engrg., ASCE (2002) 128 (2), 129-132.

[13] Ferro V., La sistemazione dei bacini idrografici, $2^{\mathrm{a}}$ ed. (2006), McGraw-Hill, Milano, 848 pp. (in Italian).

[14] Genovez A., Abt S., Florentin B., Garton A., Correction for settlement of Parshall flume, J. Irr. and Drain. Engrg., ASCE (1993) 119 (6), 1081-1091.

[15] Hager W., Modified Venturi channel, J. Irr. and Drain. Engrg., ASCE (1985) 111 (1), 19-35.

[16] Hager W., Modified trapezoidal Venturi channel, J. Irr. and Drain. Engrg., ASCE (1986) 112 (3), 225241.

[17] Parshall R.L., The improved Venturi flume, Transactions ASCE (1926) 89, 841-851.

[18] Samani Z., Magallanez H., Measuring water in trapezoidal canals, J. Irr. and Drain. Engrg., ASCE (1993) 119 (1), 181-186.

[19] Samani Z., Magallanez H., Simple flume for flow measurement in open channel, J. Irr. and Drain. Engrg., ASCE (2000) 126 (2), 127-129.

\section{SUMMARY}

At first, in this paper the stage-discharge relationship of a new flume, originally proposed by Samani and Magallanez, for measuring flow discharge in open channels is reviewed. The flume is obtained inserting two semicylinders in a rectangular cross-section.

Then, the results of some experimental runs carried out using horizontal flumes characterized by different values of the contraction ratio (ranging from 0.17 to 0.81 ) are used for determining the two coefficients of the power stage-discharge equation.

Finally, the stage-discharge equation is tested using flow measurements carried out, in the period December 2004 - March 2006 in the Sicilian experimental SPA1 and SPA2 basins. Field testing of the SMBF flume is developed using discharge measurements carried out by a Khafagi-Venturi flume placed in the field measurement channel of each experimental basin.

Key words: Open channel flow; Flow measurement; Flumes; Dimensional analysis. 